\title{
Depositional feature of sandy conglomerate in Tuo128 block, Shengtuo
}

\section{area}

\section{Li Cunlei, Liu Jianmei, Gao Peng and Chen Panpan}

\author{
College of Petroleum Engineering, Liaoning Shihua University, Fushun, 113001, People's Republic \\ of China;
}

keyword: Shengtuo area, sandy conglomerate, prograded-type fan delta, sedimentary types.

Abstract.Sandy conglomerate is the major sedimentary systems in the upper fourth member of Shahejie formation in Shengtuo area. In this paper, on the base of core observation and description, sedimentary characteristics are studied in the upper fourth member of Shahejie formationin Shengtuo area. The results show that the prograded-type fan delta is the major sedimentary system in Shengtuo area. There are two major sedimentary types: traction current deposits which is the most strikingly signified by Parallel bedding sandstone containing gravel, and debris flow deposits which is the most strikingly signified bymassive bedding sandy conglomerate.

\section{Introduction}

The Tuo128 block locates at the upthrown block of Tuo-Sheng-yong tectonic zone of Dongying sag, Jiyang depresson, the north is Tuo123 block, the west is Tuo121 block, and the south is the third zone of Shengtuo oil field ${ }^{[1]}$. The integrated rich oil and gas accumulation conditions is extremely favorable. But the lack of understanding of sedimentary features and genetic types of sandy conglomerate fan leads to the low exploration success rate.

\section{The distinguish of sedimentary type}

\section{Gravity flow deposits}

Sedimentary gravity is formed by deposit sediment flow along the slope in the gravity. So thisflow also is called density flow or mass flow[2]. Abruptness and intermittent are the principal characters of this flow. Middleton and Hampton[3]divide gravity flow into debris flow, fluidized flow, grain flow and turbidity current based on Particles support mechanism. The debris flow and turbidity current are the major flow in the research area ${ }^{[4]}$.

(1) Debris-flow

Debris-flowcan also be called subaqueous debric flow, it is akindof non-Newtonian fluid formed by the flow of high sediment concentration. The fluid type is the laminar flow ${ }^{[5]}$. The relativematrix densityis as high as 2.5 . The debris-flow will stop, when the tension of the slope caused by gravity is no more than the shearing force of the debris-flow block, and then will form debris-flow lobe.

The debris-flow cuts in the semi-deep and deep lacustrine mudstone. The vertical sequence appears positive rhythm. The characteristics of sedimentsarelarge change of grain-size, complicate composition, high shale content and poor sorting property (Figure 1, A, B). The stratum of debris-flow Lobe deposit is thick, and some can even reach to several meters. The stratification is not very obvious. The common bedding in this area includes deformation bedding, massive bedding, 
and inverse graded bedding. This micro-facies almost appear low-amplitude tooth-shaped SP curves and high resistance curves.

(2) Turbidity current

Turbidity current is compound of deposit and water. The turbiditydeposit is transported by the way of suspension state. It can flow in the extremely gender slope of turbulent mechanism ${ }^{[6]}$. The flow velocity or the energy of turbulent reducing can cause the sediment to deposit rapidly. The initial deposit sediment always is coarse, following the decreasing of flow velocity, and the ratio of fine sediment increase, which became the normal bedding ${ }^{[7]}$.

\section{Traction current deposits}

The sedimentary structuresare the parallel bedding, cross bedding and scour surface erosion , which reflect the channel deposition, and well developed. Theseare the typical traction current deposits.

\section{The distinguish of sedimentary system}

li cunlei et al [8]discussed in detail the distinguish of sandy conglomerate sedimentary system from formation conditions, fluid type, sedimentary structure, lithofacies association and sedimentary sequence.

Through the coring analysis of Tuo 128, the sand of fourth subsegmental glutenite generally sandwiched between shallow lake facies and semi-deep lake facies mudstone in grey, which shows the deposition of the relative shallow water. The grit ${ }^{[9-10]}$ embraces graded bedding, the massive bedding, overlapping erosion, landslide, mud rip-up deformation structure, which load cast ball, pillowstructure and flame structure. These reflecthe gravity flowsedimentarycharacteristicstectonicsedimentary development, at the same time, and reflect the channel deposition of parallel bedding,crossbedding and reflect the hydrodynamic changes of erosion surface. Cutting and other sedimentary structures in the study area are developed. According to table 1 the system can be judged as fan delta deposition.
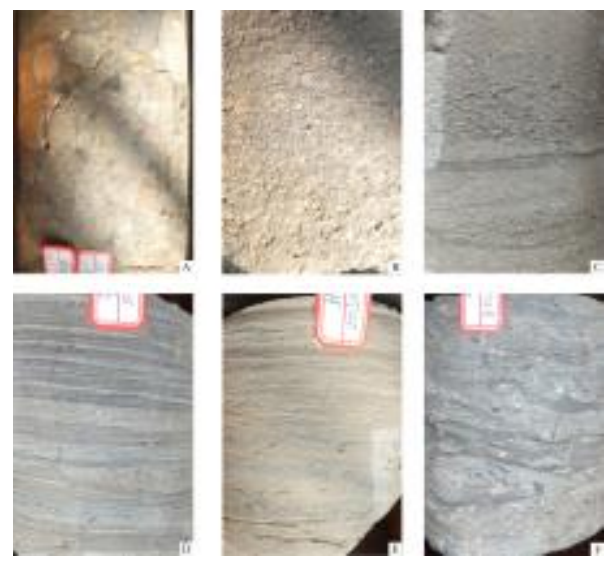

Figure 1 sandy conglomerate sedimentary structure of Tuo128 block, Shengtuo area

\section{sedimentary microfacies characteristics}

The sand on fourth submember sedimentary period is transgressive systems on whole. The fan delta is a mountain river outflowing directly into the lake basin shallow, which forms almost completely submerged fan-shaped glutenite, from near provenance, lack of land fan environment and coarsening-upward sedimentary sequence.There are lithologic,morphologyand classification of 
characteristics in the fan delta, which are similar to the piedmont alluvial fan. It can be further separated into innerfan,midfan and outerfan three subfacies.

According to the detailed core description and analysis ${ }^{[1]}$, drilling coring relates to various subfacies and microfacies. The water inlet fan delta can be further divided into innerfan,midfan and outerfan three sands subfacies. Innerfan sedimentary microfacies types is consist of braided channel and channel; midfan sedimentary microfacies types are composed of braided channel, midfan front and middle fan channel between the outerfan; sedimentary microfacies types are mainly thin sand and deep mud lake.

(1) Braided channel

Fan braided channel micro-facies : themainly mixed base of gravel rock debris bracket to support the conglomerate and sandstone, which is generally upwardly tapering of the positive cycle, clastic coarse granularity, complex component, high shale content, poorly sorting, particle size hybrid. Single layer is thickness, up to tens of meters, and often contains ash green and grey mudstone. Bedding are generally not too clear, common bedding types have the block bedding, reverse graded and positive graded bedding and unclear large cross-bedding. Rock bottom often is erose surface or the mutant contacting with the underlying layer. Spontaneous potential curves of the amplitude variation is not obvious or low amplitude of the dentate, high resistance..

Midfanbraided channel facies: sediment composition, structure controlled by contributions of provenances, conglomerate content is high, and some regions of lithology is fine.But overall lithology is thick,mainly with sandy conglomerate and sandstone.Sandstone and conglomerate are bad sorting,complex composition, unstable mineral debris and high content of matrix. Scour can be seen at sand bottom, while massive bedding, parallel bedding and medium to large cross-bedding are common.Single upwardly tapering thickness is generally from tens of centimeters to several meters, in the sand between the gray and grayish green mudstone interlayeroften consists of tens of meters thick overlay laminated sandstone ( Figure 2). Spontaneous potential curve are often gear box shape, top and bottom gradient box.

(2)Frontmidfan microfacies

The front midfan is actually a fan in the waterway extending in the direction of the basin,particle size turned to be fine, andbottom scour did not develope the same as channel region. Cross-bedding developed better than waterway,but is generally thicker than water district.Spontaneous potential curves show the teeth on funnel and bell, the scouring effect of reaction channelis reduced,andhave a certain wave transformation function.

(3) Interchannel microfacies

Mainlycomposed of from gray to dark gray, mudstone and thin sandstone, and massive beddingand small bedding structure are developed in sandstone.Sliding and deformation are also common.Owing tostrong scouring force of the braided river channel, channel changes frequently.Once a diversion, these sediments were washed thinning, or even all washed out. Spontaneous potential curves have a number of shapes like dentate, finger or tooth of bell.

(4) Thin layer sand

Regional distributionof fan delta sand body and fan end formed in the wave action is stronger in sedimentary environment, and formed in advance of the braided channel sand bodies underwent strong wave action, occurrence of lateral migration, and the connecting piece, which shows a thin layer of sand. Sand body divide into fine sandstone and glutenite sandstone, which are detritus sorting, rounded, relatively good. Thin sand and mudstone in the longitudinal direction, can grow parallel to bedding and ripple bedding with visible graded bedding and the massive bedding. Their spontaneous potential curves are interdigitating or dentate. 


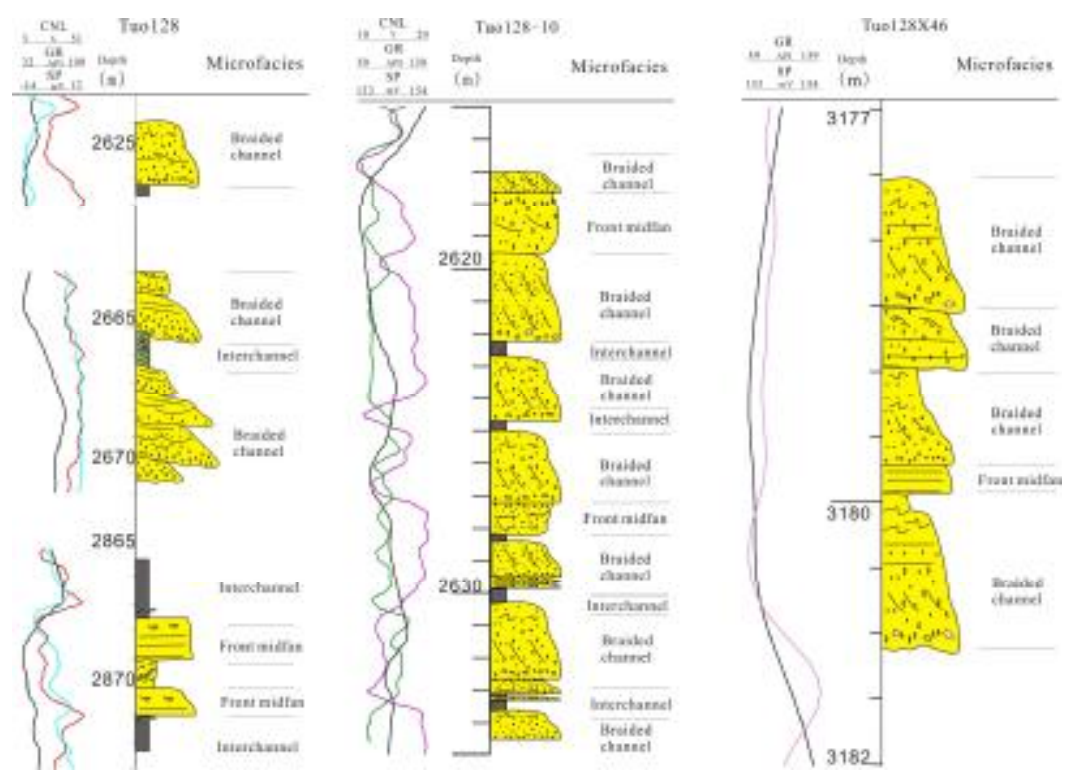

Fig.2 sedimentary sequences of tuo128 area.

\section{Conclusion}

The 128 block of Shengtuo area sand with four subsets are developed water inlet fan deltadepositional system. Sedimentary types of the massive bedding consist mainly of debris flow deposit, parallel bedding and traction current deposits, which can be further divided into three sands subfacies. There are fan sedimentary microfacies types of braided channel and channel, fan of sedimentary microfacies types of braided channel, fan in the front and middle fan channel between the fan end. Sedimentary microfacies types are mainly thin sand and half deep lake mud.

\section{Reference}

[1]Z.Jinliang,Z.Xin, Fan-delta and related turbiditic deposits on the steep slope of Dongying depression, Bohai Bay basin. Journal of China University of Geosciences,18: 314 316(2007).

[2]G. Shanmugam, High density turbidity currents: Are they sandy debris flows?. Journal of Sedimentary (1996).

[3]G .V. Middletonand M .A.Hampton, Sediment gravity flows:Mechanics of flow and deposition In: Middleton G V, Bouma A H. eds.Turbidites and Deep-Water Sedimentation

: Short Course LectureNotes, Part I. Los Angeles: 1 38(1973).

[4]L.yun,Z.rongcai,Z. guojin,H.xiaoqing, Reviews on Sediment Gravity Flow.Advances in Earth Science. 26 (2) : $157 \sim 165(2011)$.

[5]L.renzi,Z.jinliang, Advances in Geosciences DOI: 10.12677/AG.2014.42013 Oct 15, 2014

[6]Shanmugam .G,Ten turbidite myths . Earth Science Reviews, 58: 311 341( 2002).

[7]L.cunlei, Z. Jinliang, S.mingshui, S. chaoqun, S. Ning, L. Ting, Fine Division and Correlation of Glutenite Sedimentary Periods Based on Sedimentary Facies Inversion-A Case Study from the Paleogene Strata of Upper Es4 in the Yanjia Area, Dongying Depression.Acta Geologica Sinica, 85 (6) : 1008 1018(2011). 
[8]L.cunlei, L. ting, X. lianJun, Sedimentary Characteristics of Dereliction Fan Delta in the Second Member ofDainan Formation, Huangjue Area, Gaoyou Depression.Periodical of Ocean University of China, 40(4): $65 \sim 71$ (2010).

[9]Z. jinliang, Z. Xin, T The glutenite sedimentary facies and hydrocarbon distribution in the Upper Fourth Member of Shahejie Formation in Shengtuo Area. Acta Sedimentol Sinica.26 (3) : 361 368 (2008).

[10]Z.Xin,Z.Jinliang, Depositional feature and mode of sand-conglomerate bodies in the lower third member of Shahejie Formation in Shengtuo area.Acta Petrolei Sinica.2008.29 (4) : 533 538.

[11]Bouma. A. H, In sedimentology of some flysch deposits: a graphic approach to facies interpretation. Amsterdam: Elsevier. 168(1962) 